\title{
SERPENTINIZAÇÃO E METASSOMATISMO EM ROCHAS ULTRAMÁFICAS: DISCUSSÃO DAS CARACTERÍSTICAS E RECOMENDAÇÕES PARA O TRATAMENTO GEOQUÍMICO
}

\author{
ADELIR J. STRIEDER*
}

\begin{abstract}
ULTRAMAFIC ROCKS SERPENTINIZATION AND METASOMATISM: DISCUSSION OF THEIR CHARACTERISTICS AND RECOMENDATIONS FOR GEOCHEMICAL TREATMENT. This paper intends a general revision about the petrochemical aspects of the ultramafic rocks metamorphic modification. At first, the extreme mechanisms of mass transfer is distinguished: intergranular diffusion and transport by solution; their relative importance depends on the water content of the system. The geological conditions in which the mass transfer occurs are described as contact/juxtaposition, or as infiltration, and available literature examples are also presented. The geological features used to recognize the mechanisms and the conditions of the mass transfer include metasomatic zoning, structures, chemical components mobility, mineral phase stability etc, and they are discussed in the paper. At last, based on the results of experimental investigations, a method is developed to verify which chemical components were transfered during the serpentinization and metasomatism of the ultramafic rocks. The method is developed to put in evidence the elements that do not develop chemical potencial gradients.
\end{abstract}

Keywords: Ultramafic rocks, serpentinization, metasomatism, geochemical mass transfer.

\begin{abstract}
RESUMO Este artigo procura fazer uma revisão geral sobre os aspectos petroquímicos das modificações metamórficas das rochas ultramáficas. A princípio, por meio da revisão, tomou-se possível distinguir os mecanismos pelos quais a transferência de massa é efetuada: difusão intergranular e transporte por solução são os termos extremos cuja importância relativa depende da quantidade de água disponível e em circulação no sistema. As condições geológicas nas quais esta transferência de massa ocorre são descritas como contato/justaposição, ou como infiltração, e exemplos disponíveis na literatura são apresentados. As feições geológicas usadas para reconhecer os mecanismos e as condições geológicas da transferência de massa incluem a zonação metassomática, estruturas, mobilidade dos componentes químicos, estabilidade das fases minerais etc, e elas são apresentadas e discutidas, ou apenas referidas no texto. Ao final, baseado nos resultados de investigações experimentais, é desenvolvido um método para verificar quais componentes químicos foram transferidos durante a serpentinização e o metassomatismo das rochas ultramáficas. $\mathrm{O}$ método procura pôr em evidência os elementos que não desenvolvem gradientes de potencial químico.
\end{abstract}

Palavras-chaves: Rochas ultramáficas, serpentinização, metassomatismo, transferência geoquímica de massa.

INTRODUÇÃO De um modo geral, é amplamente conhecido que (1) as rochas ultramáficas apresentam uma mineralogia original essencialmente anidra muito pouco estável sob quaisquer condições de metamorfismo e que (2) a sua composição química é, por vezes, muito contrastante com a composição química das rochas com as quais estão em contato. A primeira característica faz com que a mineralogia original seja transformada numa série de minerais hidratados (serpentina, brucita, talco, anfibólio,...), cuja formação pode ser unicamente explicada pela introdução de $\mathrm{OH}^{-}$nas rochas ultramáficas; os minerais que comumente predominam como resultado deste processo de transformação metamórfica são as serpentinas, de onde vem a denominação de SERPENTINIZAÇÃO para tal processo. A segunda característica faz com que seja estabelecido um gradiente químico entre a rocha ultramáfica e a rocha encaixante, de modo a criar condições para que determinados elementos químicos sejam trocados entre as duas rochas de acordo com o grau de contraste químico global e com as condições de temperatura, de pressão, de $\mathrm{fO}_{2}$ e de $\mathrm{a}_{\mathrm{H} 2 \mathrm{O}}$ do metamorfismo; estas trocas de elementos químicos entre duas rochas definem a essência dos PROCESSOS METASSOMÁTICOS e resultam num arranjo geométrico simples de zonas minerais ao longo dos contatos.

Estes dois processos de transformação, entretanto, normalmente ocorrem em conjunto nas rochas ultramáficas e pode ser muito difícil separar geoquimicamente a influência de um, ou de outro. $\mathrm{O}$ estudo destes processos tem servido para determinar a mobilidade de certos componentes químicos e para traçar considerações acerca das condições químicas em que se desen- volveram. No final, tenta-se determinar se a serpentinização realizou-se sob composição química constante (Hosteller et al 1966, Page 1967, Coleman \& Keith 1971), ou sob volume constante (Thayer 1966,1967, Condie \& Madison 1969). Esta discussão surge pela dificuldade de se avaliar criteriosamente o grau de modificação química global das rochas ultramáficas sujeitas à serpentinização e ao metassomatismo.

As características dos processos de serpentinização e de metassomatismo fazem com que as texturas originais da rocha ultramáfica sejam freqüentemente obliteradas em maior, ou em menor grau, o que pode dificultar seriamente a identificação do seu protolito. Por outro lado, os elementos químicos normalmente utilizados para definir a afinidade geoquímica das rochas básicas a ácidas ocorrem em quantidades muito pequenas nas rochas ultramáficas e os elementos menores mais comuns nestas rochas não possuem, ainda, estudos adequados de sua mobilidade geoquímica frente a tais processos de transformação. O conjunto destas características toma muito difícil não só a definição da afinidade geoquímica da rocha ultramáfica, como também a identificação do seu protolito.

No Brasil, o tratamento geoquímico de rochas ultramáficas tem recebido uma atenção mais acentuada desde o reconhecimento petrográfico de derrames komatíticos (Sabóia 1979). Uma observação geral dos trabalhos que têm sido realizados sobre rochas ultramáficas revela que, apesar da manifesta preocupação com o fator "modificação da composição química global", os dados analíticos vêm sendo utilizados de maneira equivocada em diversos diagramas composicionais. Deste modo, este artigo não pretende fornecer um simples resumo dos 
diversos trabalhos que apresentam as características gerais de tais processos de transformação metamórfica, mas uma síntese objetiva e qualitativa das diferentes maneiras como estes processos devem ser encarados e a maneira como os dados analíticos devem ser utilizados.

A análise de diversos artigos a respeito de metassomatismo e a necessidade de fornecer um quadro amplo de condições geológicas destes processos levaram a questionar a utilização de determinados conceitos. Neste sentido, parece necessário explicitar claramente os conceitos utilizados de processo e de mecanismo:

1. PROCESSO é o ato e/ou o efeito de transformar, ou de modificar a constituição petrológica de um determinado "material" geológico em outra que se apresente em equilíbrio com as condições geológicas vigentes; é o conjunto de fenômenos que causam a transformação.

2. MECANISMO, por outro lado, são os meios através dos quais uma transformação é efetuada.

Assim, pode-se falar de processos metamórficos como a modificação petrológica efetuada em estado sólido/sub-sólido e classificá-los de acordo com as condições geológicas como se apresentam: a. sem modificação da composição química global da rocha (metamorfismo isoquímico), ou b. com modificação da composição química da rocha (metassomatismo).

Em termos de tratamento teórico das transformações metamórficas em rochas ultramáficas, é conveniente separar arbitrariamente o "processo" metassomático do "processo" de serpentinização. Isto permitirá que as características mais importantes de cada "processo" sejam distinguidas, isoladas e tratadas separadamente, de modo que a influência de cada um sobre a composição química global da rocha ultramáfica possa ser avaliada com maior clareza. Esta separação não quer implicar a perda da noção de conjunto resultante da fragmentação e da dissociação de um processo único que ocorre na maioria dos casos, mas um recurso por meio do qual as modificações operadas possam ser mais globalmente entendidas. Este tipo de abordagem permite reconhecer a maneira como foram cometidos muitos dos equívocos de tratamento e de interpretação das análises qualitativa e quantitativas realizadas sobre este tipo de transformação, e como surgiram as duas correntes principais (isoquímica e isovolumétrica) de tratamento da serpentinização.

METASSOMATISMO O metassomatismo é, essencialmente, um processo metamórfico que envolve a transferência bilateral de massa e que pode ser dividido em dois tipos extremos: difusão e infilltração (Korzhinskii 1970). A separação destes dois tipos de transferência bilateral de massa, desde que entendida a característica específica do processo metassomático, é importante para distinguir as situações geológicas dentro das quais se realizam as transformações metassomáticas e para fixar os parâmetros a partir dos quais o modelamento petroquímico das transformações metassomáticas pode ser realizado.

O metassomatismo por difusão dá-se pela transferência intergranular de massa: o "material é transferido pela difusão através das soluções intersticiais estacionárias" (Korzhinskii 1970). A transferência é controlada pelo gradiente químico estabelecido a partir da justaposição, sob condições metamórficas, de duas rochas com composição química global muito contrastante. As paragêneses resultantes deste metassomatismo não demonstram uma saturação em qualquer dos componentes difundidos e isto pode significar que a taxa de reação é maior do que a taxa de difusão; portanto, a taxa de reação controla todo este processo metassomático. Este tipo de metassomatismo é mais freqüentemente referido à zonação mineralógica materializada nos contatos da rocha ultramáfica com a rocha encaixante.

O metassomatismo por infiltração, por outro lado, está condicionado à presença de rochas de grande permeabilidade, de modo que um "material" qualquer possa migrar e adicionar, ou remover determinados componentes químicos de acordo com as condições físico-químicas locais. As rochas ultramáficas apresentam, contudo, uma pequena permeabilidade e a migração de qualquer "material" deve aproveitar zonas de fratura, as quais vão controlar tanto o metassomatismo, quanto uma parte da serpentinização da rocha ultramáfica original. Korzhinskii (1970) considera que "os componentes (químicos) sejam transferidos pelo movimento de soluções aquosas que percolam [...] ao longo dos contatos dos grãos, ou fluem ao redor de porções individuais mais compactas das rochas". O metassomatismo por infiltração pode ser visualizado, então, como a introdução de material com composição química muito contrastante àquela da rocha ultramáfica. Desta maneira, podese considerar uma transferência bilateral de massa estabelecida pela difusão química, ou por transporte por solução através do contato de dois tipos de materiais reagentes. Isto permite sugerir que a análise da transformação metassomática deva considerar, inicialmente, o sistema rocha ultramáfica como aberto (metassomatismo por infiltração) ou fechado (metassomatismo no contato rocha ultramáfica-rocha encaixante) à livre circulação de "material" no seu interior.

É neste ponto que se torna necessário discutir os conceitos de processo e de mecanismo. A classificação de Korzhinskii (1970) distinguiu dois "tipos extremos" de metassomatismo, hierarquizados a nível de processo; portanto, estes "tipos" implicam condições, ou situações geológicas onde a transformação é realizada. A descrição e a caracterização dos dois tipos de metassomatismo por Korjzhinskii (1970), reflete no entanto, muito mais os meios (soluções estacionárias, ou percolantes) através dos quais a transformação é efetuada, do que um tipo de transformação. A diferença de conceito é, por vezes, mascarada pela idéia de que a transferência de massa envolve necessariamente soluções, mas pode ser percebida na seguinte passagem do texto de Korzhinskii (1970): "os processos de infiltração e de difusão estão sempre combinados na natureza. As soluções percolam ao longo dos contatos de grãos, ou fluem ao redor de porções individuais compactas da rocha, e a substituição dos grãos e das porções individuais se dá como resultado da difusão de seus componentes". Este conflito de conceitos fez com que muitos pesquisadores (p. ex.: Brady 1975a,b, 1977) passassem a caracterizar os tipos de processo de Korzhinskii (1970) como mecanismos de transferência de massa.

Analisada a questão conceituai e considerada a descrição anterior do processo metassomático, pode-se sugerir uma ordenação diferente para os fenômenos relacionados ao metassomatismo:

1. o PROCESSO metassomático pode ser dividido em dois tipos principais: infiltração e contato/justaposição. Estes dois tipos podem estar associados ou não; isto depende das condições locais onde a transformação ocorre (sistema aberto ou fechado).

2. a transferência de massa envolvida no metassomatismo se dá através de dois MECANISMOS principais, ou extremos: difusão intergranular e transporte por solução; a predominância de um, ou de outro mecanismo depende da quantidade de componentes fluidos que é colocada em contato, ou que se infiltra na rocha ultramáfica.

Sob qualquer condição (contato, ou infiltração), o metassomatismo produz um arranjo regular de zonas mono, bi, ou triminerálicas dispostas concentricamente ao longo dos contatos, ou simetricamente ao longo de fraturas. $\mathrm{O}$ número de minerais presentes em cada zona metassomática depende do número de componentes que estão sendo transferidos através do contato inicial e da cinemática das reações metamórficas envolvidas para determinadas condições de temperatura, de pressão, de $\mathrm{fO}_{2}$, de $\mathrm{a}_{\mathrm{H} 2 \mathrm{O}}$ e de $\mathrm{a}_{\mathrm{co} 2}$. $\mathrm{O}$ tratamento teórico e a análise do tipo de zoneamento metassomático, de acordo com o número de componentes em difusão, são amplamente discutidos por Brady (1977); esse artigo estabelece um marco importante na modifi- 
cação do tipo de abordagem dado às zonas metassomáticas desenvolvidas em rochas ultramáficas e os seus aspectos mais relevantes serão oportunamente enfatizados neste texto.

$\mathrm{O}$ zoneamento metassomático relacionado às rochas ultramáficas é mais claramente observado quando elas estão em contato com rochas silicosas e foram conjuntamente submetidas a metamorfismo regional. A tipologia das zonas metassomáticas produzidas guarda relação bastante íntima com o grau metamórfico, conforme tem sido salientado desde o trabalho de Phillips \& Hess (1936), e é atualmente simplificado da seguinte forma:

a. serpentinito, talco+magnesita, talco, clorita, rocha encaixante silicosa: é o zoneamento desenvolvido em condições de baixo grau metamórfico (Fig. 1A);

b. serpentinito, talco+magnesita, talco, tremolita+clorita, clorita, rocha encaixante: é o zoneamento desenvolvido em condições de $\mathrm{T}$ intermediária entre o baixo e o médio grau metamórfico (Fig. 1B);

c. serpentinito, talco+magnesita, talco, actinolita+clorita, clorita, biotita, rocha encaixante albitizada ou não: desenvolve-se em condições metamórficas que eqüivalem a fácies anfibolito inferior (Fig. 1C);

d. talco+olivina, talco+magnesita, talco, hornblenda, biotita, albita, rocha encaixante: assinala condições metamórficas de grau médio avançado (Fig. 1D).

A Figura 1 apresenta os diagramas AMS introduzidos por Brady (1977); neles estão indicadas as variações e as compatibilidades minerais decorrentes da transferência metassomática de massa para cada um dos zoneamentos descritos acima. Os diagramas AMS são capazes também de definir o contato inicial conforme a apreciação realizada até aqui, porque mostram que as transferências químicas envolvem preferencialmente $\mathrm{SiO}_{2}$ e $\mathrm{MgO}$ e, portanto, justificam o posicionamento das zonas metassomáticas derivadas da rocha encaixante e da rocha ultramáfica em diferentes níveis de conteúdo de $\mathrm{A}_{2} \mathrm{O}_{3}$.

Petrograficamente, é possível avaliar a mobilidade de determinados componentes químicos a partir da observação das relações de substituição entre as fases minerais. Estas observações são mais rigorosamente realizadas em amostras obtidas ao longo de um perfil único de transformação metassomática; porém, quando não é possível obter amostras sistemáticas ao longo de um perfil único, a mobilidade poderá ser qualitativamente avaliada a partir de amostras selecionadas que representem todas as zonas metassomáticas. De um modo geral, o metassomatismo por difusão no contato entre rochas ultramáficas e rochas quartzo-feldspáticas tem deixado sucessivamente registrado o avanço das zonas mais externas sobre as zonas mais internas pela substituição do talco por clorita+anfibólio e da serpentina por talco \pm carbonato. A zona metassomática de clorita, embora avance predominantemente sobre a rocha quartzo-feldspática encaixante, também pode avançar sobre a zona de talco (baixo grau metamórfico), ou de tremolita para marcar os estágios de maior mobilidade do $\mathrm{A}_{2} \mathrm{O}_{3}$ e formar uma zona metassomática, inicialmente delgada, de anfibólio com Al (actinolita $\rightarrow$ hornblenda).

O tratamento geoquímico dado ao processo de transformação metamórfica sofrida pelas rochas ultramáficas tem enfrentado um problema fundamental para a verificação de quais os componentes químicos que são transferidos: onde está o contato inicial entre a rocha ultramáfica e a sua encaixante? $\mathrm{O}$ estabelecimento equivocado deste contato inicial tem levado a uma avaliação incorreta do sentido da transferência de massa e da mobilidade geoquímica dos componentes. A discussão do metassomatismo por difusão (Brady 1977) mostra que a transferência de massa entre duas rochas de composição química muito contrastante se estabelece a partir de fluxos de componentes que possuem um forte gradiente no potencial químico. O fluxo de componentes químicos não é unilateral, como vinha sendo sugerido, até então, por diversos trabalhos (Curtis \& Brown 1969,1971, Carlswell et al. 1974, Frost 1975, Leach \&
Rogers 1978, Pfeifer 1981); o fluxo é bilateral, pois determinados componentes químicos são introduzidos na rocha ultramáfica, enquanto outros são removidos em direção à rocha encaixante. Assim, tanto a rocha ultramáfica, quanto a rocha encaixante vão mostrar modificações de sua composição química original, de acordo com a extensão do fluxo estabelecido.
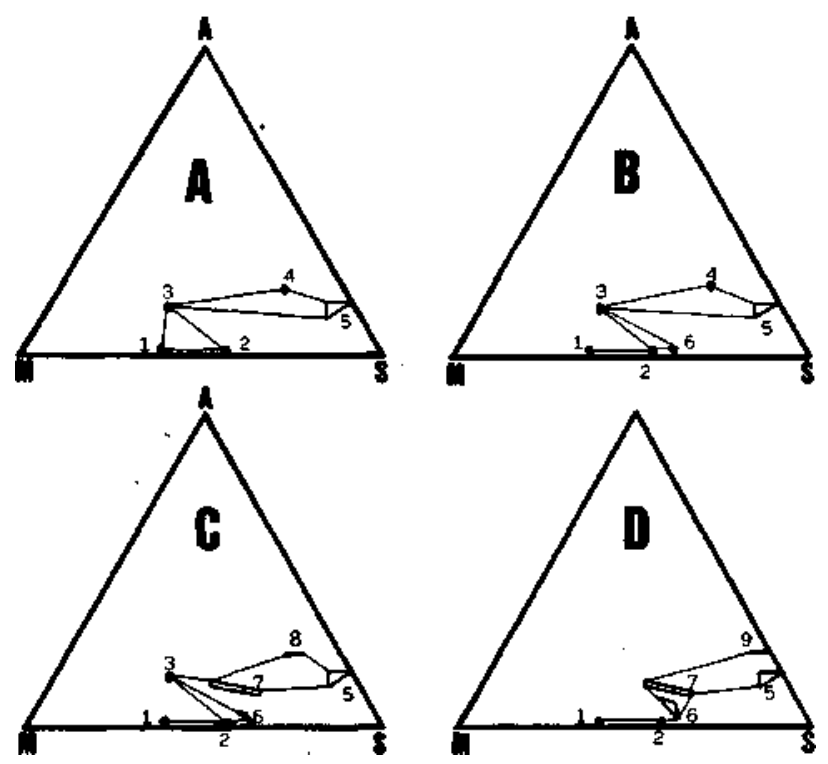

Figura 1 - Relações paragenéticas do metassomatismo de contato no diagrama AMS. (A) baixo grau, (B) fácies epídotoanfibolito, $(\boldsymbol{C})$ anfibolito $e(\boldsymbol{D})$ alto grau metamórfico (modificado a partir de Brady 1977). 1. Serpentina, 2. Talco, 3. Clorita, 4. Rocha encaixante alterada, 5. Rocha encaixante, 6. Tremolita $\rightarrow$ Hornblenda, 7. Biotita, 8. Rocha encaixante albitizada, 9. Albita

Figure 1 - Paragenetic relationships of the contact metassomatism in the AMS diagram. (A) low grade, (B) epidote-ampnibolite facies, (C)amphibolite facies and (D) high metamorphic grade (modified from Brady 1977). 1. Serpentine, 2. Talc, 3. Chlorite, 4. Modified coubtry rock, 5. Country rock, $\mathbf{6}$. Tremolite $\rightarrow$ Hornblende, 7. Biotite, 8. Albitized country rock, 9. Albite

A partir desta caracterização, surge o conceito de MARCADOR INERTE, que é tido como a materialização do contato inicial entre os dois tipos de rochas "reagentes". O marcador inerte pode ser uma característica de natureza física, ou de natureza química. O artigo de Brady (1977) fixa, inicialmente, as razões $\mathrm{Al} / \mathrm{Cr}$ e $\mathrm{Al} / \mathrm{Ni}$ como os marcadores inertes químicos neste tipo de metassomatismo e, a partir destas razões, consegue definir, perfeitamente, o limite entre as zonas metassomáticas de talco e de clorita como o contato inicial (marcador inerte físico). A definição deste contato inicial já era indicada por Phillips \& Hess (1936), mas foi negligenciada em muitos trabalhos de modelamento petrogenético destas transformações. A partir do artigo de Brady (1977), houve condições de definir, quimicamente, a zona da clorita como o resultado da transformação metassomática da rocha encaixante silicosa pela adição preferencial de $\mathrm{MgO}$ e pela remoção de $\mathrm{SiO}_{2}$. Porém, dados de natureza petrográfica que pudessem comprovar esta transformação ainda não haviam sido suficientemente expostos; neste sentido, texturas reliquiares da rocha encaixante preservadas dentro da zona metassomática de clorita foram descritas por Strieder (1989) e são apresentadas na fotomicrografia 1.

Para se fixar uma determinada razão entre elementos químicos como um marcador inerte, é necessário que se tenha uma noção bem clara do comportamento geoquímico dos elementos utilizados em todas as condições de temperatura e de pressão 
do metamorfismo. O estudo mais aprofundado, que avaliou o comportamento geoquímico dos elementos mais importantes, foi realizado por Sanford (1982) e definiu a razão $\mathrm{Cr} / \mathrm{Ti}$ como a melhor marcadora de uma forte descontinuidade química e mineralógica; esta descontinuidade "sobreviveu" à transferência de massa que foi estabelecida. Fixada esta razão, Sanford verificou que as zonas metassomáticas derivadas a partir da rocha ultramáfica (talco, talco+carbonato, anfibólio+clorita) apresentam um aumento de volume mais como resultado de uma adição de $\mathrm{SiO}_{2}, \mathrm{CO}_{2}, \mathrm{FeO}, \mathrm{CaO}$ e $\mathrm{Al}_{2} \mathrm{O}_{3}$ à rocha ultramáfica do que a perda de $\mathrm{MgO}$. Este desequilíbrio volumétrico na transferência de massa para a rocha ultramáfica é compensado pela diminuição de volume nas zonas metassomáticas derivadas a partir da rocha encaixante. Com estas conclusões, Sanford (1982) atribui a diminuição do conteúdo de $\mathrm{Cr}^{3+}$ através das zonas metassomáticas da rocha ulíramáfica ao efeito da diluição ocasionada pelo aumento de volume, já que não são observadas quaisquer evidências da difusão do $\mathrm{Cr}^{3+} \mathrm{em}$ direção à rocha encaixante; inversamente, o aumento no conteúdo de $\mathrm{Ti}^{4+}$ da rocha encaixante em direção à zona da clorita é conseqüência da diminuição de volume que ocorre neste lado do contato inicial.

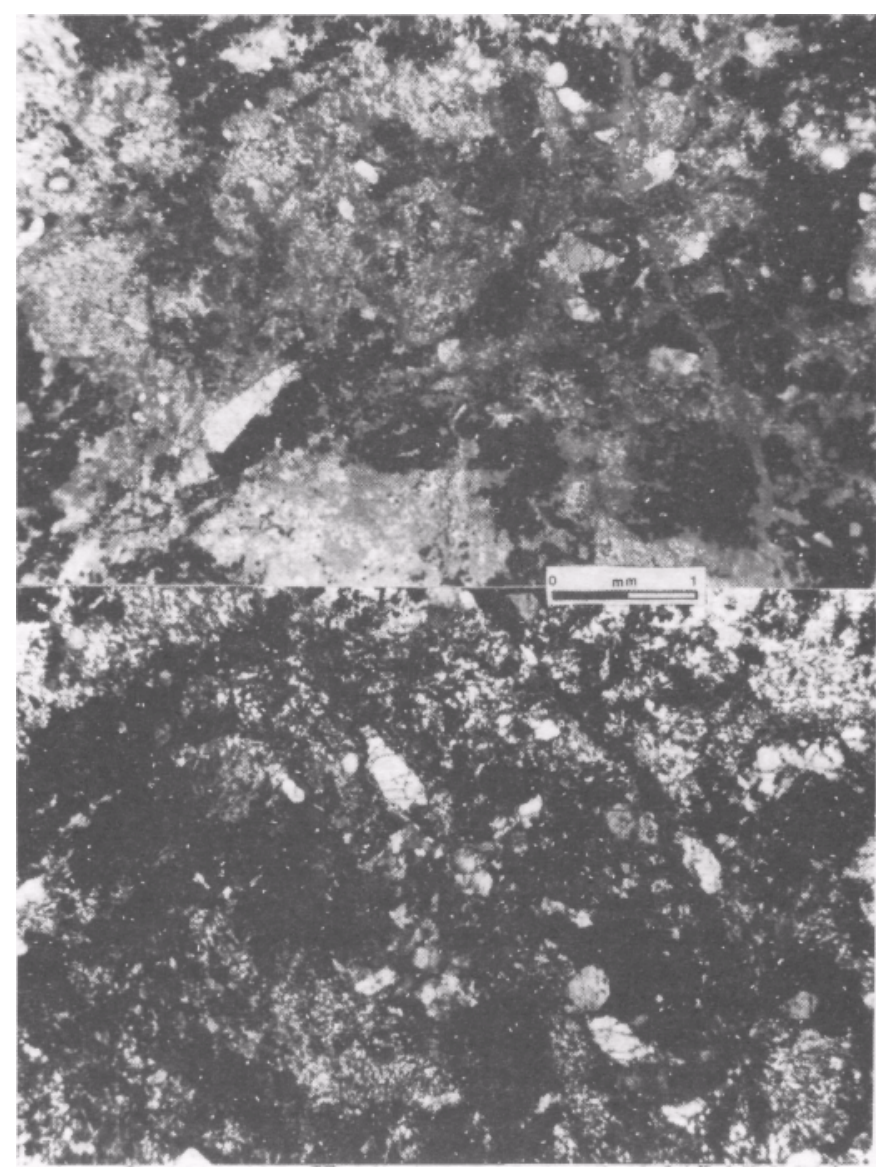

Fotomicrografia 1 - Textura reliquiar da rocha encaixante quartzo-feldspática observada na zona metassomática da clorita

Photomicrography 1 - Reliquiar texture of a quartz-feldspatic country rock in the chlorite metasomatic zone

A observação detalhada do artigo de Sanford (1982) permite verificar que existe uma seqüência de elementos cuja mobilidade está estritamente relacionada ao aumento da temperatura metamórfica: $\mathrm{CaO}, \mathrm{Al}_{2} \mathrm{O}_{3}, \mathrm{Na}_{2} \mathrm{O}+\mathrm{K}_{2} \mathrm{O}, \mathrm{FeO}$. Esta mobilidade química parece estar muito bem marcada na variação da composição mineralógica dos zoneamentos apresentados anterior- mente e, principalmente, na variação da composição do anfibólio. O aparecimento do anfibólio (tremolita) na seqüência de zonas metassomáticas marca o início da transferência de $\mathrm{CaO}$ em direção à rocha ultramáfica; o aumento da temperatura metamórfica cria condições para que apareçam, sucessivamente, a actinolita e a hornblenda como decorrência da maior mobilidade do $\mathrm{Al}_{2} \mathrm{O}_{3}$, do $\mathrm{Na}_{2} \mathrm{O}+\mathrm{K}_{2} \mathrm{O}$ e do $\mathrm{FeO}$. A zona metassomática de anfibólio, então, é especificamente muito sensível a quaisquer modificações na mobilidade geoquímica dos elementos. Por outro lado, a remoção de $\mathrm{CaO}$, de $\mathrm{FeO}$ e de $\mathrm{Al}_{2} \mathrm{O}_{3}$ da zona metassomática da clorita para a formação da zona de anfibólio implica a dissolução da clorita e na cristalização gradativa de biotita com o aumento da temperatura metamórfica.

Esta caracterização qualitativa da transferência de massa entre a rocha ultramáfica e a sua encaixante é de ordem geral e, certamente, possui variações locais em função das condições de pressão, de $\mathrm{fO}_{2}$, da $\mathrm{a}_{\mathrm{H} 2 \mathrm{O}}$ e da $\mathrm{a}_{\mathrm{co} 2}$ do metamorfismo. Sanford (1982) mostra que, por exemplo, a dissolução do plagioclásio e da biotita da rocha encaixante metassomatizada e o aproveitamento de $\mathrm{Na}^{+}$e de $\mathrm{K}^{+}$na formação de anfibólio dá origem, em baixo grau metamórfico, a um excedente de massa que não pode ser absorvido em espécies minerais portadoras de $\mathrm{Na}^{+}$e de $\mathrm{K}^{+}$na zona de clorita, nem ser transferido em direção à rocha encaixante para ser depositado como albita e/ou como biotita numa estreita zona que marca a frente de avanço da zona da clorita sobre a rocha encaixante.

A partir desta caracterização genérica da mobilidade geoquímica, é possível perceber-se que a utilização indiscriminada das razões $\mathrm{Al}^{3+} / \mathrm{Cr}^{3+}$ e $\mathrm{Al}^{3+} / \mathrm{Ni}^{2+}$ como marcadores do contato inicial, conforme é sugerido por Brady (1977), não é aconselhada para zoneamentos metassomáticos estabelecidos sob condições de temperatura superior àquela da fácies epidoto-anfibolito. Esta situação, que decorre da mobilidade do $\mathrm{Al}_{2} \mathrm{O}_{3}$ a temperaturas mais elevadas, foi posteriormente investigada por Fowler et al. (1981) e resultou numa importante apreciação crítica do trabalho de Brady (1977). De maneira independente, Sanford (1982) também viu dificuldade em utilizar inadvertidamente as razões propostas por Brady e, a partir do estudo que realizou, passou a sugerir a razão $\mathrm{Cr}^{3+}$ (1977) $\mathrm{Ti}^{4+}$ como marcadora do contato inicial.

A partir de construções gráficas que utilizem os resultados das investigações realizadas por Sanford (1982), é possível verificar a mobilidade geoquímica dos componentes considerados em cada caso; deve-se observar, no entanto, que as zonas metassomáticas mostram efeitos de aumento e de diminuição de volume. Propõe-se, aqui, utilizar gráficos binaries, onde o eixo das ordenadas representa uma razão catiônica do tipo $\mathrm{M} / \mathrm{N}$ e o eixo das ordenadas a quantidade cationica do componente $\mathrm{N}$ (p. ex.: $\mathrm{Cr}^{3+} / \mathrm{Ti}^{4+}$ vs. $\mathrm{Ti}^{4+}$ ). Estes gráficos devem conter análises de todas as zonas metassomáticas e das rochas iniciais para que as seguintes observações possam ser feitas:

a. as análises de cada tipo de rocha definem uma linha média (trend) para o comportamento geoquímico dos elementos considerados;

b. as linhas médias das zonas metassomáticas de talco e de anfibólio+clorita são aproximadamente paralelas à linha média da rocha ultramáfica inicial, desde que a transformação metassomática tenha deixado imóveis os elementos químicos considerados. Neste caso, a diminuicão no conteúdo $\mathrm{de} \mathrm{Ti}^{4+}$ nas zonas metassomáticas da rocha ultramáfica se faz de maneira proporcional à diminuição no conteúdo de $\mathrm{Cr}^{3+}$ como conseqüência da diluição destes elementos com o aumento de volume sofrido por estas zonas metassomáticas (Fig. 2A);

c. as linhas médias das zonas metassomáticas de clorita e/ou de biotita \pm albita também são aproximadamente paralelas à linha média da rocha encaixante inicial, se a transformação ocorreu de forma isoquímica para os elementos considerados. Isto indica que o aumento proporcional no conteúdo de $\mathrm{Ti}^{4+}$ e de $\mathrm{Cr}^{3+}$ resulta da diminuição significativa do volume da rocha encaixante metassomatizada (Fig. 2A); 

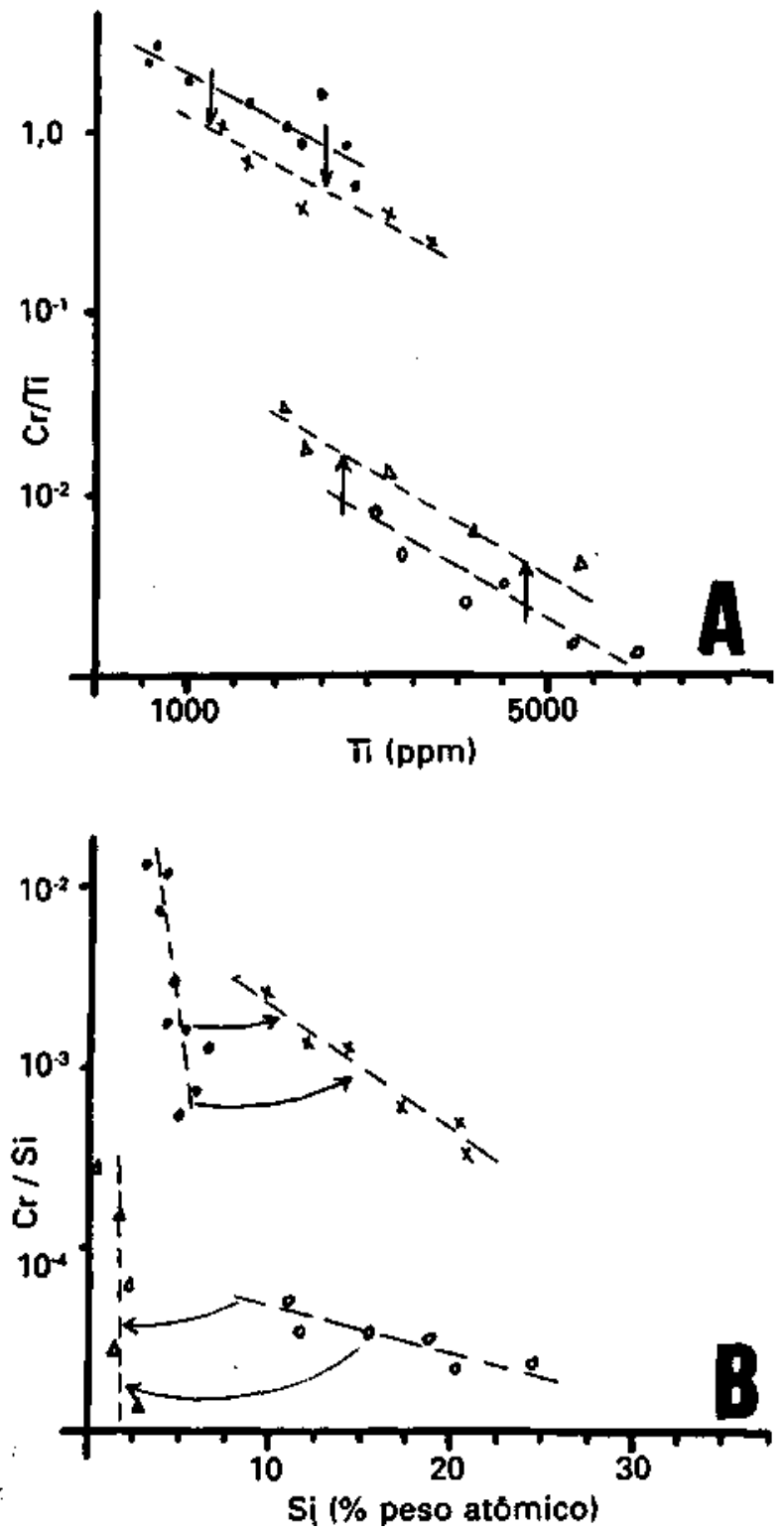

Figura 2 - Diagramas binaries que mostram a modificação no conteúdo global dos elementos entre as zonas metassomáticas (A) e no conteúdo relativo entre os elementos de cada zona metassomática $(\boldsymbol{B})$. - Serpentinito, $x$ talco xisto, $\Delta$ clorita xisto, o rocha encaixante

Figure 2 - Binary diagrams showing the changes in the global amount of chemical elements between metassomatic zones (A) and in the relative amount of the chemical elements in each metasomatic zone (B). $\bullet$ Serpentinite, $i$ Talc schist, $\Delta$ Chlorite schist, Ocountry rock

d. o não paralelismo entre as linhas médias de qualquer zona metassomática e a linha média da rocha da qual derivam indica que um dos elementos químicos obteve mobilidade sob as condições de $\mathrm{T}$, de $\mathrm{P}$, de $\mathrm{fO}_{2}, \ldots$ em que se processou a transformação metassomática (Fig. 2B). Neste caso, o deslocamento das linhas médias das zonas metasomáticas se faz no sentido de aumentar, ou de diminuir o caimento com relação à linha média da rocha inicial e indica, respectivamente, a remoção, ou a introdução de um determinado componente químico na rocha inicial.

SERPENTINIZAÇÃO A serpentinização pode ser considerada como um processo que envolve a transformação metamórfica dos minerais ígneos originais de uma rocha ultra- máfica em minerais predominantemente do grupo das serpentina. Em termos gerais, esta transformação pode ser obtida a partir da simples hidratação de uma rocha ultramáfica sob condições metamórficas. Assim, é muito importante levar em consideração os meios através dos quais a hidratação pode ocorrer, para que se possa apreciar previamente a possibilidade de modificação da proporção relativa entre os elementos químicos que compunham a rocha ultramáfica original submetida à serpentinização.

A hidratação das rochas ultramáficas está certamente condicionada a sua permeabilidade global e à existência de um fluxo constante de soluções essencialmente aquosas através dela. Portanto, o princípio inicial da análise da serpentinização deve considerar se o sistema rocha ultramáfica é aberto, ou é fechado, de acordo com a mesma perspectiva utilizada na análise do metassomatismo. Deste modo, é muito importante observar, primeiramente, as condições iniciais de serpentinização por meio das características petrográficas desenvolvidas nas rochas ultramáficas. As informações obtidas dos estudos petrográficos representam a interrelação complexa das influências exercidas pela temperatura, pelp tipo de deformação, pela pressão, pela anjo e por variáveis que normalmente possuem menor importância $\left(\mathrm{fO}_{2}, \mathrm{a}_{\mathrm{CO} 2}, \mathrm{fS}_{2}\right.$, etc). A abordagem conjunta de algumas destas variáveis e a apreciação dos resultados petrográficos da complexa influência destas variáveis sobre o processo de serpentinização foram realizados por Wicks \& Whittaker (1977) e resultaram na classificação de oito distintos regimes de serpentinização; porém, por possuir um cunho generalista e uma base essencialmente microscópica, este artigo foi posteriormente complementado por um estudo dos registros micro e macroscópicos da deformação impressa antes, durante e depois de instalado o processo de serpentinização (Wicks 1984a,b,c). A utilização cuidadosa das características petrográficas pode permitir a identificação de várias fases de serpentinização numa única unidade de rocha ultramáfica (p. ex.: Laurent \& Hébert 1979) e fazer com que o tratamento geoquímico da rocha ultramáfica seja mais ou menos complexo, de acordo com a natureza de cada fase de serpentinização.

A condição de sistema aberto ou fechado, implica, respectivamente, numa alta ou numa baixa relação "água"/rocha; representam, na verdade, as condições extremas de soluções estacionárias e percolantes que são colocadas em contato, ou que se infiltram na rocha ultramáfica. Assim, é necessário considerar as características gerais das duas situações: 1. uma alto relação "agua'Vrocha, de modo semelhante aos sistemas hidrotermais, dá condições para que alguns componentes originais possam ser removidos por "lixiviação" (transporte por solução), enquanto outros são adicionados de acordo com as condiçõos físico-químicas locais; neste caso, a serpentinização envolve a modificação da proporção relativa dos elementos químicos da rocha ultramáfica e, portanto, pode ser considerada como um processo metassomático por infiltração de "material" essencialmente aquoso. Isto significa que a "serpentinização por infiltração" pode ser encarada como um caso extremo do metassomatismo por infiltração, pois, ao invés da troca predominante de componentes tipo $\mathrm{MgO}, \mathrm{SiO}_{2}, \mathrm{FeO}$, $\mathrm{A}_{2} \mathrm{O}_{3}$ etc., a mudança química global envolve somente a adição de $\mathrm{OH}^{-}$à rocha ultramáfica.

A transferência de massa, desconsiderada a $\mathrm{OH}^{-}$, ainda é bilateral, mas pode apresentar forte predominância em um sentido (adição ou remoção) e, portanto, pode tender a ser encarada como unilateral. A remoção de componentes químicos da rocha ultramáfica ocorre porque a sua taxa de transporte por solução é maior do que a sua taxa de reação com os componentes químicos introduzidos pela solução aquosa circulante e, ao mesmo tempo, ocorre quando as condições físicoquímicas locais não permitem que os componentes removidos da rocha ultramáfica sejam precipitados como espécies minerais na própria rocha; no outro sentido, a adição de componentes químicos à rocha ultramáfica é principalmente controlada 
pela sua taxa de reação com os componentes químicos mobilizados, mas pode aumentar se as condições físico-químicas locais permitirem que eles sejam precipitados como espécies minerais a partir da solução aquosa circulante. $\mathrm{O}$ fato de a taxa de transporte por solução ou de difusão ser mais acentuada do que a taxa de reação faz com que não haja condições para se estabelecer equilíbrios químicos locais dentro da zona afetada por estas transformações metamórficas. Em termos petrográficos, a ausência de equilíbrios químicos locais está refletida na ocorrência de contatos corrosivos entre os indivíduos minerais que fazem parte de uma mesma zona metassomática e não só entre os indivíduos minerais que estão na frente de avanço das zonas metassomáticas.

Embora a adição ou a remoção de componentes químicos possa ser pequena, o processo de "serpentinização por infiltração" vai desenvolver um zoneamento mineralógico simetricamente disposto ao longo das fraturas. Este zoneamento envolve minerais como a lizardita/antigorita, a brucita e a crisotila fibroso e, em casos extremos, pode possuir zonas de talco + magnesita, de talco e de magnesita + quartzo posicionadas no centro do zoneamento.

A transformação metamórfica por meio do transporte por solução está representada no exemplo descrito por Labotka \& Albee (1979). No entanto, aqueles autores argumentam em favor da transferência unilateral de $\mathrm{SiO}_{2}$ e de $\mathrm{H}_{2} \mathrm{O}$ em direção à rocha ultramáfica. A argumentação não é suficientemente consistente, porque Labotka \& Albee (1979) não fazem referência ao estado de equilíbrio entre os indivíduos minerais que compõem as zonas metassomáticas; assumem, apenas, que existe equilíbrio químico local para facilitar a análise quantitativa realizada. Labotka \& Albee (1979) não consideram, também, a composição altamente magnesiana da olivina, que, hidratada, deve produzir uma paragênese tipo antigorita+brucita \pm magnesita, pois a antigorita não consegue acomodar todo o Mg e há a necessidade de "precipitar" acumuladores de Mg. Assim, a presença de pequena quantidade de brucita, isolada ou em vênulas, pode sugerir que a solução percolante removeu $\mathrm{MgO}$, ao invés de adicionar $\mathrm{SiO}_{2}$.

A análise quantitativa das modificações químicas sofridas por uma rocha ultramáfica no processo de "serpentinização por infiltração" deve ser precedida por uma análise qualitativa da mobilidade de seus diferentes componentes químicos. Independente do mecanismo de transferência de massa, e da existência ou da ausência de equilíbrio químico local, as características físicas desenvolvidas pelo processo de "serpentinização por infiltração" são muito semelhantes àquelas desenvolvidas no metassomatismo abordado na seção anterior. A análise qualitativa da mobilidade dos componentes químicos no processo de "serpentinização por infiltração" pode, portanto, ser realizada com os mesmos critérios utilizados para analisar o metassomatismo.

As características físicas e químicas do "material" que se infiltra e que circula na rocha ultramáfica podem gradativamente deslocar o mecanismo de transferência de massa do transporte por solução (sistemas com alta relação "água"/ rocha) para a difusão intergranular, que predomina em sistemas com baixa relação "agua"/rocha. Isto significa que a mobilidade dos componentes químicos será fortemente reduzida com a predominância da difusão intergranular. 2. o outro extremo do processo de serpentinização ocorre, portanto, quando o sistema rocha ultramáfica é fechado à livre circulação de qualquer solução. Neste caso, a hidratação se dá pela difusão intergranular de $\mathrm{OH}^{-}$, a qual possui mobilidade química muito acentuada em direção à rocha ultramáfica submetida a condições metamórficas. Este tipo de caracterização também permite encarar a serpentinização realizada em sistema fechado como um processo metassomático colocado no extremo oposto do metassomatismo abordado na seção anterior e, desta forma, possibilita que seja realizada uma análise qualitativa da extensão das modificações na proporção relativa dos diferentes componentes químicos da rocha ultramáfica em conjunto com a análise qualitativa do metassomatismo. A partir desta análise qualitativa, é possível detectar amostras de serpentinito que possuam algum grau de modificação química dos elementos mais importantes, e descartá-las dos estudos que envolvam a avaliação da natureza petrogenética das rochas ultramáficas.

A análise qualitativa discutida até aqui tem sido, ainda, muito negligenciada nos trabalhos que abordam estes tipos de transformações metamórficas. Isto se deve à inovação recente que este tipo de caracterização geral vem criando nos critérios de análise das transformações em rochas ultramáficas, mas principalmente às profundas raízes deixadas por dois métodos de tratamento: 1. o isovolumétrico e $\mathbf{2}$. o isoquímico.

O método ISOVOLUMÉTRICO está fundamentado 1. na observação de texturas pseudomórficas, 2. no não-reconhecimento da importância do fraturamento desenvolvido durante o alojamento e durante a transformação dos corpos ultramáficos, 3. no fato de se assumir uma alta mobilidade geoquímica para o componente $\mathrm{Mg}(\mathrm{OH})_{2}$ (brucita) e, muitas vezes, 4. na própria presença de bordos metassomáticos zonados e de rodingitos. A partir destas características, assume-se um tratamento geoquünico com critérios essencialmente iguais àqueles adotados para o tratamento de processos de lixiviação supergênica. A utilização desta argumentação e destes critérios foi inicialmente desenvolvida por Thayer $(1966,1967)$ e por Condie \& Madison (1969).

O método ISOQUÍMICO, de outro modo, reconhece a possibilidade de se preservar texturas pseudomórficas onde há modificação de volume e a importância dos fraturamentos na delimitação de um maior espaço aos corpos ultramáficos. De certa forma, o método também antecipou uma distinção entre metassomatismo e serpentinização, embora, nos primeiros trabalhos, considere o caráter isoquímico a partir da nãoocorrência de depósitos de brucita ou de magnesita junto aos corpos ultramáficos. O início desta discussão é creditado aos artigos de Hosteller et al. (1966), de Page (1967) e de Coleman \& Keith (1971).

A primeira importante justificativa, de natureza química, em favor da serpentinização isovolumétrica foi dada por Thayer (1966) com a utilização do Diagrama de Shteinberg (Fig. 3). As discussões e as conclusões levantadas por Thayer (1966) a partir dos diagramas estão baseadas na comparação de amostras que são provenientes de diversos maciços ultramáficos e que não possuem qualquer controle quanto ao condicionamento do processo de serpentinização. Deste modo, é natural que haja uma dispersão acentuada das análises locadas nos diagramas, pois, além da grande complexidade do processo de transformação metamórfica abordado anteriormente, também deve ser levada em conta a grande variação mmeralógica e composicional que normalmente ocorre nos maciços ultramáficos. Este tipo de preocupação orientou o trabalho de Coleman \& Keith (1971), que foi realizado em um corpo peridotítico alojado na Formação Franciscana (melange ofiolítica da orogênese Mesozóica no Oeste dos E.U.A.) aqueles autores tiveram o cuidado de amostrar porções com constituição mineralógica homogênea que representassem vários graus de serpentinização e que não possuíssem serpentina fibrosa em veios ou em vênulas. Os resultados analíticos alcançados por Coleman \& Keith (1971) foram locados no Diagrama de Shteinberg (Fig. 3) e mostraram que não houve mudança na quantidade relativa dos óxidos $\mathrm{SiO}_{2}, \mathrm{MgO}, \mathrm{FeO}^{*}, \mathrm{Al}_{2} \mathrm{O}_{3}, \mathrm{Cr}_{2} \mathrm{O}_{3}$ e $\mathrm{NiO}$.

A discussão da serpentinização como isoquímica ou como isovolumétrica surgiu pela dificuldade no estabelecimento de critérios inequívocos em favor de um ou de outro modo de transformação. Atualmente, as rochas ultramáficas que estão quase completamente serpentinizadas representam, ainda, uma importante limitação na avaliação das possíveis mudanças químicas introduzidas por estas transformações metamórficas. Esta dificuldade decorre da impossibilidade de se utilizar o 
Diagrama de Shteinberg para acompanhar a serpentínização e da dificuldade de se fixar um "marcador inerte" através do qual as mudanças químicas apareçam claramente.

Os critérios utilizados por estes métodos de tratamento do processo de transformação metamórfica de rochas ultramáficas permitiam assumir, de antemão, as condições restritas a partir das quais é realizada toda a quantificação do processo. A quantificação baseava-se no balanço de massa de reações químicas que possuem inúmeros fatores desencadeantes e controladores e que, portanto, necessitam de simplificações drásticas para terem seu comportamento modelado. Esta abordagem profundamente químico-quantitativa tem servido, então, para justificar tanto um quanto o outro método de tratamento, conforme sejam escolhidas as reações químicas.

Atualmente, diversos trabalhos experimentais têm sido realizados a respeito da cinemática de reações entre os diversos minerais que compõem as rochas ultramáficas, e têm demonstrado uma interdependência muito grande entre a transformação da mineralogia original, a cristalização da rnineralogia metamórfica e a composição das "soluções" intergranulares (Hemley et al. 1977a,b, Frantz \& Popp 1979, Filippidis 1982, Janecky \& Seyfried 1986, Puhan \& Metz 1987). Contudo, não tem ficado claro, nestes trabalhos, que tipo de mecanismo de transferência de massa está atuando. Tampouco é especificada ou considerada explicitamente a sua abrangência dentro das condições onde ocorre a modificação química dos corpos ultramáficos (infiltração ou contato); esta definição é importante na medida em que permite situar o contexto geológico onde o processo ocorre e, assim, traçar o tipo de abordagem que o tratamento qualitativo deve seguir.

CONCLUSÕES E RECOMENDAÇÕES A caracterização qualitativa geral do processo de transformação metamórfica das rochas ultramáficas permite distinguir, de uma maneira mais conveniente, os mecanismos de transferência de massa, o papel do condicionamento geológico para a transferência de massa e a interrelação destes fatores no desenvolvimento de zoneamentos metassomáticos e na modificação da composição química global de rochas ultramáficas (Fig. 4).
O principal ponto de mudança na abordagem da transferência de massa diz respeito aos mecanismos através dos quais ela ocorre. A difusão intergranular tem sido usualmente considerada no tratamento qualitativo e quantitativo de reações metamórficas que, embora facilitadas pela presença de $\mathrm{H}_{2} \mathrm{O}$, não estão condicionadas à sua livre circulação (Fisher 1970, Elliot 1973, Brady 1975a,b, Frantz \& Mao 1976, 1979, Weare et al 1976, Gray \& Durney 1979, Rutter 1983, Wheeler 1987). No outro extremo, a transferência de massa se dá pelo "transporte por solução" de caráter essencialmente aquoso; este mecanismo de transferência de massa atua nos sistemas hidrotermais abertos, onde a relação "agua'Vrocha é muito elevada (Norton \& Knapp 1977, Giggenbach 1981, Henley \& Ellis 1983, Norton 1984). Considera-se, então, que a transferência de massa ocorre pela atuação de dois mecanismos: a difusão intergranular e o transporte por solução.

O condicionamento geológico, por sua vez, é muito importante para a definição do mecanismo de transferência de massa. Assim, o sistema rocha ultramáfica pode se apresentar fechado à infiltração de qualquer material e, em condições de metamorfismo, permite apenas que, criado o gradiente geoquímico, a transferência de massa se dê por difusão intergranular no contato com a rocha encaixante; este é o caso dos exemplos descritos por Curtis \& Brown $(1969,1971)$, por Fowler et al. (1981) e por Strieder \& Nilson (1992). Contudo, modificado o condicionamento geológico de modo que haja infiltração de material no sistema rocha ultramáfica, quer seja ao longo do contato com a rocha encaixante, quer seja através de fraturas na rocha ultramáfica, o mecanismo de transferência de massa vai depender da natureza do material infiltrante (quantidade de $\mathrm{H}_{2} \mathrm{O}$ e $\mathrm{CO}_{2}$ relativamente à quantidade de óxidos metálicos e/ ou alcalinos) e da possibilidade deste material circular livremente através do sistema rocha ultramáfica. A quantidade relativa de $\mathrm{H}_{2} \mathrm{O}+\mathrm{CO}_{2}$ e de óxidos metálicos e alcalinos $\left(\mathrm{MO}_{\mathrm{n}}\right.$ $+\mathrm{AkO}_{\mathrm{n}}$ ) é o aspecto principal para a definição da natureza do material infiltrante e, em decorrência, do mecanismo de transferência de massa. A partir desta relação e das condições geológicas da infiltração, podem ser delineados casos extremos

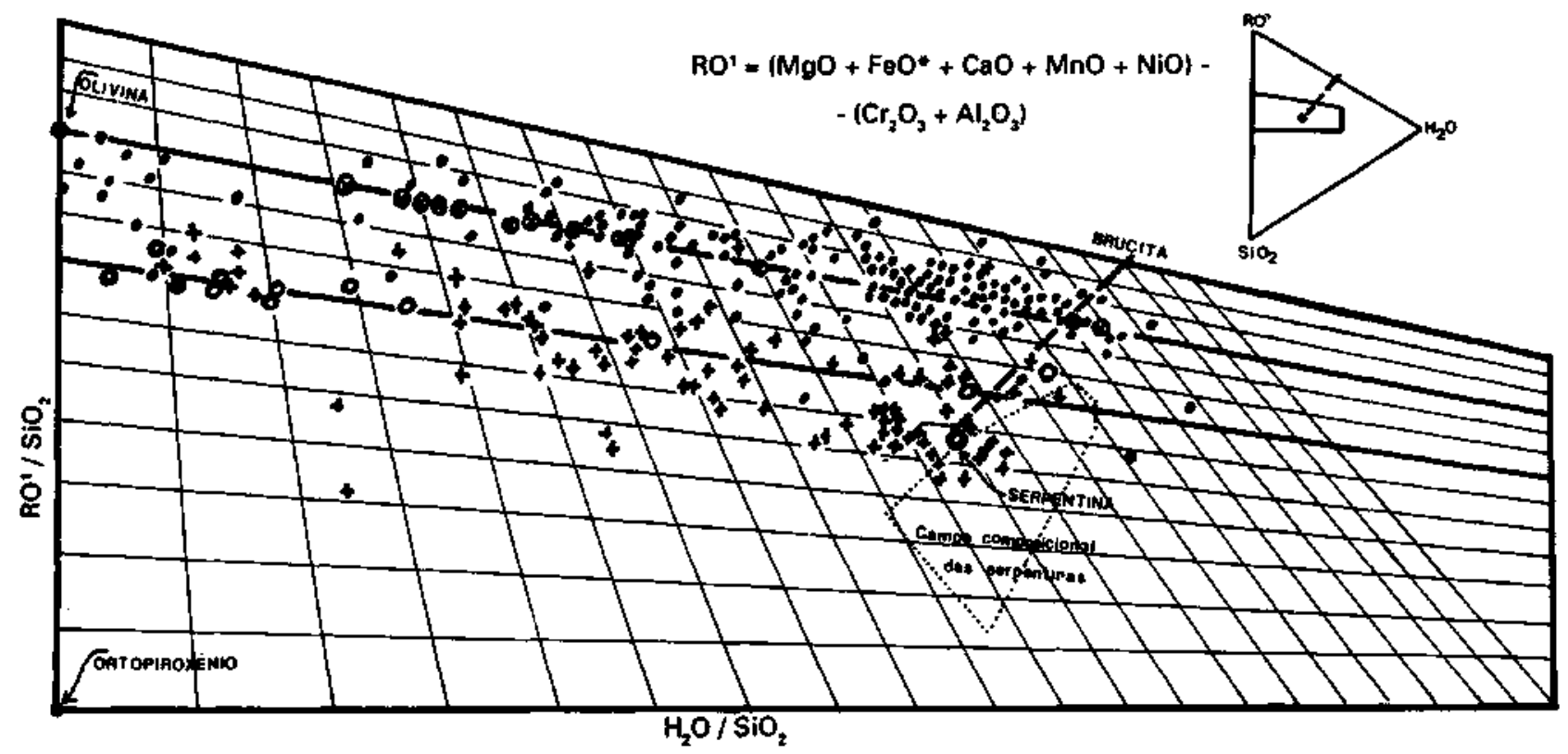

Figura 3 - Diagrama molecular de Shteinberg que apresenta a modificação compositional de rochas ultramáficas com a introdução de água; compara as análises apresentadas por Thayer (1966, ponto e cruz) e por Coleman \& Keith (1971, círculos abertos)

Bgure 3 - Molecular Shteinberg diagram showing the compositional modification of ultramafic rocks with water introduction; the diagram compare Thayer's (1966, closed circles and crosses) and Coleman \& Keith's (1971, open circles) analysis 
do metassomatismo por infiltração e situados mais claramente alguns exemplos abordados anteriormente:

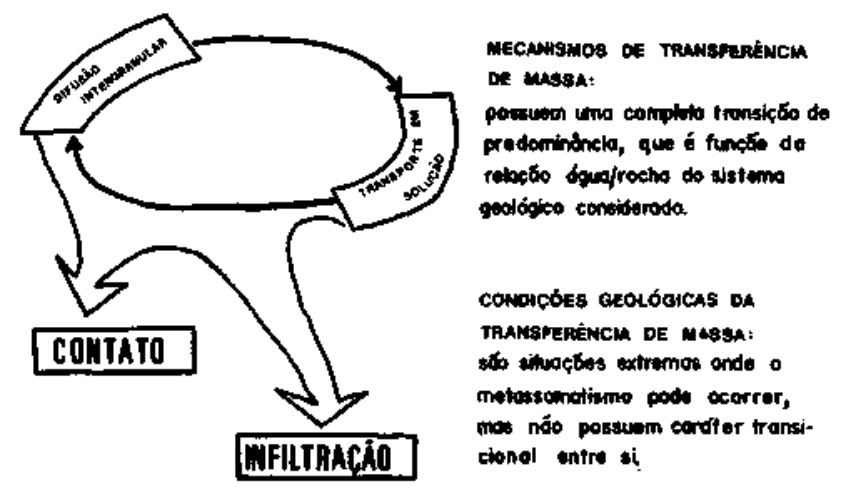

Figura 4 - Esboço da inter-relação entre os mecanismos de transferência de massa e as condições geológicas do sistema onde esta transferência ocorre

Figure 4 - Sketch of the relationship between the mass transfer mechanisms and the geological conditions of the systems where this transfer occur

1. baixa relação $\left(\mathrm{H}_{2} \mathrm{O}+\mathrm{CO}_{2}\right) /\left(\mathrm{MO}_{\mathrm{n}}+\mathrm{AkO}_{\mathrm{n}}\right)$ no material que infiltra as fraturas, sem que haja circulação livre na rocha ultramáfica; a transferência de massa é predominantemente realizada por difusão intergranular durante as reações metamórficas que se estabelecem. Este parece ser o caso do exemplo descrito por Carlswell et al. (1974), já que a zonação metassomática desenvolvida é semelhante àquela identificada no metassomatismo de bordo dos corpos ultramáficos;

2. uma quantidade aproximadamente igual de $\left(\mathrm{H}_{2} \mathrm{O}+\mathrm{CO}_{2}\right)$ e de $\left(\mathrm{MO}_{\mathrm{n}}+\mathrm{AkO}_{\mathrm{n}}\right)$ resulta numa maior mobilidade química e física para o material infiltrante; a mobilidade química decorre da maior quantidade de componentes fluidos, os quais permitem que uma maior quantidade de massa seja transferida em solução através da rocha ultramáfica. Um exemplo muito interessante é descrito por Pfeifer (1981), que identificou uma série de efeitos do metassomatismo de contato e de infiltração, onde o $\mathrm{CO}_{2}$ parece ter tido uma influência significativa;

3. uma alta relação $\left(\mathrm{H}_{2} \mathrm{O}+\mathrm{CO}_{2}\right) /\left(\mathrm{MO}_{\mathrm{n}}+\mathrm{AkO}_{\mathrm{n}}\right)$ no material infiltrante e a possibilidade da livre circulação desta solução "aquosa" através da rocha ultramáfica são condições semelhantes àquelas existentes nos sistemas geotermais, onde a transferência de massa ocorre por transporte em solução. A pequena quantidade de óxidos metálicos ou alcalinos em solução faz com que o metassomatismo não desenvolva zonas de clorita, ou de anfibólio, mas zonas que indiquem a remoção de $\mathrm{MgO}$ e/ou a adição de $\mathrm{SiO}_{2}$. Bons exemplos deste tipo de situação são apresentados por Labotka \& Albee (1979) e por Laurent \& Hébert (1979), embora a quantidade de "solução aquosa" que percolou na rocha ultramáfica não tenha sido suficientemente grande para desenvolver zonas mais amplas e mais intensas de metassomatismo.

Em qualquer um destes casos, o metassomatismo pode ser estudado por meio de uma amostragem regular e transversal às zonas minerais desenvolvidas e de um cuidadoso tratamento geoquímico. A amostragem regular pode ser dispensada para o metassomatismo por difusão ao longo do bordo da rocha ultramáfica, desde que a localização das amostras em relação a cada zona mineral seja cuidadosamente avaliada e que o tratamento geoquímico seja utilizado apenas qualitativamente para avaliar a extensão das modificações químicas na rocha original. Neste caso, as amostras de serpentinito que não indiquem modificação química podem ser utilizadas na investigação da natureza petroquímica original da rocha ultramáfica. Aqui, é muito importante frisar que a análise das modificações químicas deve sempre preceder qualquer tipo de investigação petroquímica que diga respeito ao caráter geoquünico do protolito ultramáfico original. Do mesmo modo, é também muito importante fazer o reconhecimento geológico do condicionamento das transformações metassomáticas macroscopicamente observáveis e, a partir disto, fazer um planejamento de amostragem de acordo com as características reconhecidas e as suas relações com os casos de transformação metamórfica discutidos neste artigo e, naturalmente, com os objetivos da investigação a ser procedida.

Realizada a coleta e a análise petrográfica e química das amostras, o tratamento geoquímico deve seguir os procedimentos discutidos neste trabalho. $\mathrm{O}$ primeiro passo consiste em definir os elementos menores cuja proporção relativa não foi modificada pela serpentinização ou pelo metassomatismo. Normalmente, tem-se utilizado o $\mathrm{Ti}^{4+}$ e o $\mathrm{Cr}^{3+}$, mas o $\mathrm{Ni}^{2+}$ e o $\mathrm{Co}^{2+}$ também podem fornecer uma resposta adequada para este tipo de tratamento. A partir da determinação dos elementos químicos menores cuja proporção relativa não foi modificada, devese utilizar a razão entre dois deles para avaliar a intensidade das trocas químicas dos elementos maiores. O estudo das transformações metamórficas nas rochas ultramáficas segundo este tipo de tratamento marca uma grande evolução a partir dos trabalhos de investigação experimental de Brady (1977) e de Sanford (1982); porém, a literatura geológica disponível não tem, ainda, tratado estas transformações metamórficas de forma mais global e, por isso, foram referidos apenas trabalhos que tratam isoladamente da serpentinização e do metassomatismo. Um exemplo de abordagem mais global deste problema e da complexidade que envolve este tipo de tratamento geoquünico pode ser encontrado no trabalho desenvolvido por Strieder \& Nilson (1992).

Por fim, a análise qualitativa pode dar lugar a análise quantitativa da transferência de massa e isso requer, necessariamente, amostragens contínuas ao longo dos perfis de transformação de qualquer dos casos discutidos acima. Esta análise quantitativa deve envolver, primeiramente, a verificação da magnitude das mudanças de volume nas zonas metassomáticas e, em seguida, o processamento das transferências de elementos maiores a partir de parâmetros fornecidos pela modificação da concentração dos elementos menores e do volume de cada zona metassomática.

Agradecimentos $\mathrm{O}$ autor agradece aos Prof. Ariplínio A. Nilson (UnB), Léo A. Hartmann (UFRGS) e Raul M. Khuyunjian (UnB) pelas críticas e sugestões que permitiram melhorar a organização e a clareza deste artigo.

\section{REFERÊNCIAS BIBLIOGRÁFICAS}

BRADY, J.B. 1975a. Reference frame and diffusion coefficients. Am. J. Sci, 275:954-983.

BRADY, J.B. 1975b. Chemical components and diffusion. Am. J. Sci., 275:1073-1088.

BRADY, J.B. 1977. Metasomatic zones in metamorphic rocks. Geochim. Cosmochim. Acta, 41:113-125.

CARLSWELL, D.A.; CURTIS, CD.; KANARIS-SOTIRIOU, R. 1974. Vein metasomatism in peridotite at Kalskaret near Tafjord, South Norway. $J$. Petrol., 15:383-402.
COLEMAN, R.G. \& KEITH, T.E. 1971. Chemical study of serpentnization Burro Mountains, California.J. Petrol., 12(2):311-328.

CONDffi, K.C. \& MADISON, J.A. 1969. Compositional and volume changes acompanying progressive serpentinization of dunites from the Webster-Addie ultramafic bodies, North California. Am. Mineral., 54(7/8):1173-1179.

CURTIS, C.D. \& BROWN, RE. 1969. The metasomatic development of zoned ultramafic bodies in Unst, Shetland. Contr. Mineral. Petrol, 24(4):275-292. 
CURTIS, CD. \& BROWN, RE. 1971. Trace dement behaviour in the zoned metasomatic bodies of Unst, Shetland. Contr. Mineral Petrol, 31(2):87-93.

ELLIOT, D. 1973. Diffusion flow laws in metamorphic rocks. Bull Geol Soc. Am., 84:2645-2664.

FHJPPIDIS. A. 1982. Experimental study of the serpentinization of Mg- Fe-Ni olivines in the presence of sulfur. Can. Mineral, 20(4):567-574.

FISHER, G.W. 1970. The application of ionic equilibria to metamorphic differentiation: an exemple. Contr. Mineral Petrol, 29:91-103.

FOWLER, M.B.; WILLIAMS, RR.;WINDLEY,B.F. 1981. The metasomatic development of zoned ultramafic balls from Fiskenaesset, West Greenland. Mineral Mag., 44:171-177.

FRANTZ, J.D. \& MAO, H.K. 1976. Bimetasomatism resulting from intergranular diffusion: I - a theoretical model for monomineralic reaction zone columns. Am. J. Sci, 276:817-840.

FRANTZ, J.D. \& MAO, H.K. 1979. Bimetasomatism resulting from intergranular diffusion: $\mathrm{n}$ - prediction of multimineralic zone sequences. Am. J. Sci, 279:302-323.

FRANTZ, J.D. \& POPP, R.K. 1979. Mineral solution equilibria: I - an experimental study of complexing and thermodynamic properties of aqueous $\mathrm{MgCl}_{2}$ in the system $\mathrm{MgO}-\mathrm{SiO}_{2}-\mathrm{H}_{2} \mathrm{O}-\mathrm{HCL}$ Geochim. Cosmochim. Acta, 43:1223-1239.

FROST, B.R. 1975. Contact metamorpbism of serpentinites: chloritic blackwall and rodingite at Paddy-go-easy, Central Cascades, Washington. J. Petrol, 16:272-313.

GIGGENBACH, W.F. 1981. Geothermal mineral equilibria. Geochim. Cosmochim. Acta, 44(12):2021-2031.

GRAY, D.R. \& DURNEY, D.W. 1979. Crenulation cleavage differentiation: implication of solution-deposition processes. J. Struct. Geol, 1(1): 73-80.

HEMLEY, J.J.; MONTOYA, J.W.; CHRIST, C.L.; HOSTETLER, RB. 1977 a. Mineral equilibria in the $\mathrm{MgO}-\mathrm{SiO}_{2}-\mathrm{H}_{2} \mathrm{O}$ system: I - talc-chrysotile forsterite-brucite stability relations. Am. J. Sci, 277:322-351.

HEMLEY, JJ.; MONTOYA, J.W.; SHAW, D.R.; LUCE, R.W. 1977. Mineral equilibria in the $\mathrm{MgO}-\mathrm{SiO}_{2}-\mathrm{H}_{2} \mathrm{O}$ system: $\mathrm{H}$ - Talc-antigorite-forsteriteanthophyllite-enstatite stability relations and some geologic implications in the system. Am. J. Sci, 277:353-383.

HENLEY, R.W. \& ELLIS, A J. 1983. Ancient and modern geothermal systems: a geochemical review. Earth Sci Rev., 19(1): 1-50

HOSTETLER, P.B.; COLEMAN, R.G.; MUMPTON, FA; EVANS, B. 1966. Brucite in alpine serpentinites. Am. Mineral, 51:78-98.

JANECKY, D.R. \& SEYFRIED W.E., Jr., 1986. Hydrothermal serpentinization of peridotite within the oceanic crust: experimental investigation of mineralogy and major element chemistry. Geochim. Cosmochim. Acta, 50(6): 1357-1378.

KORZHINSKII,D.S. 1970. Theory of Metassomatic Zoning. London, Oxford University Press. 162 p. (Trad. J. Agrell).

LABOTKA, T.C. \& ALBEE, A.L. 1979. Serpentinization of the Belvidere Mountain ultramafic body, Vermont: mass balance and reaction at the metasomatic front Can. Mineral, 17(4):831-845.

LAURENT, R. \& HÉBERT, Y. 1979. Paragenesis of serpentinite assemblages in harzburgite tectonite and dunite cumulate from the Quebec Appalachians. Can. Mineral., 17(4):857-869.

LEACH, T.M. \& ROGERS, K.A. 1978. Metasomatism in the Wairere serpentinite, King County, New Zealand. Mineral Mag., 42:45-62.
NORTON, DX. 1984. Theory of hidrothermal systems. Ann. Rev. Earth Planet. Sci, 12:155-177.

NORTON, D.L. \& KNAPP. R. 1977. Transport phenomena in hydrothermal system: the nature of porosity. Am. J. Sci, 277:913-916.

PAGE, NJ. 1967. Serpentinization considered as a constant-volume metasomatic process: a discussion. Am. Mineral, 52:545-549.

PFEIFER, H-R. 1981. A model for fluids in metamorphosed ultramafic rocks: $\mathrm{m}$ - mass transfer under ampbibolite fades conditions in olivine-enstatite rocks of the Central Alps, Switzerland. Bull Mineral, 104(6):834-847.

PHILLIPS, A.H. \& HESS, H.H. 1936. Metamorphic differentiation at contacts between serpentinites and siliceous country rocks. Am. Mineral., 21:333-362.

PUHAN, D. \& METZ, P. 1987. Experimental equilibrium data for the reactions 3 dolomite +4 quartz $+1 \mathrm{H}_{2} \mathrm{O} \rightarrow 1$ talc +3 calcite $+3 \mathrm{CO}_{2}$ and 5 talc 6 calcite +4 quartz $\rightarrow 3$ tremolite $+6 \mathrm{CO}_{2}+2 \mathrm{H}_{2} \mathrm{O}$ at a total gas pressure of 5.000 bars. N. Jarb. Min. Mh., 11: 515-520.

RUTTER, EH. 1983. Pressure solution in nature: theory and experiments J. Geol Soc. London, 140:725-740.

SABÓIA, UN. 1979. Os greenstones belts de Crixás e Goiás, GO. Bol Informativo SBG/NCO, 9:43-72.

SANFORD, RJF. 1982. Growth of ultramafic reaction zones in greenschist to amphiboiite facies metamorphism. Am. J. Sci, 282:543-616.

STTREDER, AJ. 1989. Geologia, Petrologia e Tectdnica dos Corpos de Serpentinito e Rochas Encaixantes, Abadiâràa (GO). Brasília. 208 p. (Dissertação de Mestrado, IG/UnB).

STRIEDER. A J. \& NILSON, A.A. 1992. Estudo petrológico de alguns fragmentos tectônicos da melange ofiolítica em Abadiânia (GO): I - O protolito dos corpos de serpentinito. Rev. Bras. Geoc., 22(3):338-352.

THAYER, T.P. 1966. Serpentinization considered as a constant-volume metasomatic process. Am. Mineral., 51:685-710.

THAYER, T.P. 1967. Serpentinization considered as a constant-volume metasomatic process: a reply. Am. Mineral., 52:549-553.

WEARE, J.H.; STEPHENS, J.R.; EUGSTER, H.P. 1976. Diffusion metasomatism and mineral reaction zones: general principles and applications to feldspar reaction zones. Am. J. Sci, 276:767-816.

WHEELER, J. 1987. The significance of grain-scale stresses in the kinetics of metamorphism. Contr. Mineral Petrol, 17:397-404.

WICKS, F.J. 1984a. Deformations histories as recorded by serpentinites: I deformations prior to serpentinization. Can. Mineral.. 22(1):185-195.

WICKS, FJ. 1984b. Deformations histories as recorded by serpentinites: $\mathrm{n}$ - deformation during and after serpentinization. Can. Mineral., 22(1):197-203.

WICKS, FJ. 1984c. Deformations histories as recorded by serpentinites: in fracture patterns developed prior to serpentinization. Can. Mineral., 22(1):205-209.

WICKS, FJ. \& WHTTTAKER, EJ.W. 1977. Serpentinite textures and serpentinization. Can. Mineral, 15(3):459-488.

MANUSCRITO A724

Recebido em 19 de marco de 1992

Revisão do autor em 2 de julho de 1992

Revisão aceita em 14 de julho de 1992 